\title{
Evaluation of wind profiles from the NERC MST radar, Aberystwyth, UK
}

\author{
C. F. Lee ${ }^{1}$, G. Vaughan ${ }^{2}$, and D. A. Hooper ${ }^{3}$ \\ ${ }^{1}$ Department of Meteorology, University of Reading, UK \\ ${ }^{2}$ National Centre for Atmospheric Science, University of Manchester, Manchester, UK \\ ${ }^{3}$ Rutherford Appleton Laboratory, Oxfordshire, UK
}

Correspondence to: C. F. Lee (christopher.lee@ alumni.manchester.ac.uk)

Received: 10 March 2014 - Published in Atmos. Meas. Tech. Discuss.: 8 May 2014

Revised: 15 August 2014 - Accepted: 20 August 2014 - Published: 24 September 2014

\begin{abstract}
This study quantifies the uncertainties in winds measured by the Aberystwyth Mesosphere-StratosphereTroposphere (MST) radar $\left(52.4^{\circ} \mathrm{N}, 4.0^{\circ} \mathrm{W}\right)$, before and after its renovation in March 2011. A total of 127 radiosondes provide an independent measure of winds. Differences between radiosonde and radar-measured horizontal winds are correlated with long-term averages of vertical velocities, suggesting an influence from local mountain waves. These local influences are an important consideration when using radar winds as a measure of regional conditions, particularly for numerical weather prediction. For those applications, local effects represent a source of sampling error additional to the inherent uncertainties in the measurements themselves. The radar renovation improved the signal-tonoise ratio (SNR) of measurements, with a corresponding improvement in altitude coverage. It also corrected an underestimate of horizontal wind speeds attributed to beam formation problems, due to pre-renovation component failure. The root mean square error (RMSE) in radar-measured horizontal wind components, averaged over half an hour, increases with wind speed and altitude, and is $0.8-2.5 \mathrm{~m} \mathrm{~s}^{-1}(6-12 \%$ of wind speed) for post-renovation winds. Pre-renovation values are typically $0.1 \mathrm{~m} \mathrm{~s}^{-1}$ larger. The RMSE in radial velocities is $<0.04 \mathrm{~m} \mathrm{~s}^{-1}$. Eight weeks of special radar operation are used to investigate the effects of echo power aspect sensitivity. Corrections for echo power aspect sensitivity remove an underestimate of horizontal wind speeds; however aspect sensitivity is azimuthally anisotropic at the scale of routine observations $(\approx 1 \mathrm{~h})$. This anisotropy introduces random error into wind profiles. For winds averaged over half an hour,
\end{abstract}

the RMSE is around $3.5 \%$ above $8 \mathrm{~km}$, but as large as $4.5 \%$ in the mid-troposphere.

\section{Introduction}

Radar wind profilers have become an established tool for measuring wind profiles in the boundary layer (at UHF wavelengths), the free troposphere and lower stratosphere (at lower-UHF and VHF), and the lower mesosphere (at VHF wavelengths). They can measure wind profiles continuously, with a temporal resolution of $10 \mathrm{~min}$ or less, and a vertical resolution of $75-300 \mathrm{~m}$. As well as being valuable for research, wind profilers are increasingly used operationally by national weather services, with measurements assimilated into numerical forecasting models. For assimilation in particular, the random and systematic errors of wind profiles must be well characterised, but determining these errors is not a straightforward task. In this paper we examine in detail how the error characteristics of a Doppler beam swinging (DBS) VHF wind profiler - the Natural Environment Research Council's (NERC) MesosphereStratosphere-Troposphere (MST) radar at Capel Dewi, near Aberystwyth in mid-Wales $\left(52.4^{\circ} \mathrm{N}, 4.0^{\circ} \mathrm{W}\right)$ - changed after extensive refurbishment of the system in 2011.

The Aberystwyth MST radar (Vaughan, 2002; Table 1) operates at a frequency of $46.5 \mathrm{MHz}$ and can use any of 17 beam directions between zenith angles 0 and $12^{\circ}$. The DBS technique combines measurements from at least three beams to quantify three-dimensional winds, with more 
Table 1. Overview of the NERC MST Radar, Capel Dewi, Aberystwyth, UK.

\begin{tabular}{cccccc}
\hline Range & $\begin{array}{c}\text { Pulse Length } \\
\text { (Range Res.) }\end{array}$ & $\begin{array}{c}\text { Sampling } \\
\text { Interval }\end{array}$ & $\begin{array}{c}\text { Nyquist } \\
\text { Velocity }\end{array}$ & $\begin{array}{c}\text { Velocity } \\
\text { Resolution }\end{array}$ & $\begin{array}{c}\text { Beam } \\
\text { Width* }\end{array}$ \\
$1.65-21.0 \mathrm{~km}$ & $2 \mu \mathrm{s}(300 \mathrm{~m})$ & $150 \mathrm{~m}$ & $9.34 \mathrm{~m} \mathrm{~s}^{-1}$ & $0.15 \mathrm{~m} \mathrm{~s}^{-1}$ & $1.5^{\circ}$ \\
\hline
\end{tabular}

* One-way half-power half-width

beams improving accuracy and precision (e.g. Weber et al., 1992; Adachi et al., 2005; Cheong et al., 2008; Srinivasa Rao et al., 2008). A three-beam profiler uses one vertical and two off-vertical beams (pointing at orthogonal azimuths). The radial velocity $\left(V_{\mathrm{r}}\right)$ measured by an off-vertical beam may be decomposed into components of the vertical velocity $(w)$ and the horizontal velocity along the beam's azimuth $\left(H_{\phi}\right)($ Eq. 1 , where $\theta$ is the off-vertical zenith angle, and $\phi$ is the azimuth, of the beam).

$V_{r}(\phi)=H_{\phi} \sin \theta+w \cos \theta$

$w$ is measured directly by the vertical beam, with the two off-vertical beams measuring orthogonal values of $H_{\phi}$ each. Equation (2) relates $H_{\phi}$ to the Cartesian wind components $u$ and $v$ (eastward and northward components, respectively).

$H_{\phi}=u \sin \phi+v \cos \phi$

A four-beam system comprises four orthogonal off-vertical beams. Where the wind field is homogeneous across the beams, subtracting radial velocities from opposing beams cancels vertical velocity components ( $w \cos \phi$ in Eq. 1), leaving only the horizontal component (Eq. 3).

$H_{\phi}=\frac{V_{r}(\phi)-V_{r}(\phi+180)}{2 \sin \theta}$

A five-beam system (one vertical beam and four off-vertical beams) uses the same approach as a three-beam setup. Multiple vertical beam measurement are made in a cycle, and Eq. (1) is used to calculate $H_{\phi}$ for each off-vertical beam. Values from opposing beams are averaged to reduce errors.

The DBS method assumes temporal and spatial homogeneity of the wind field across the beams, which may be separated by several kilometres in the lower stratosphere. Where there are rapid changes in vertical velocity, vertical beam measurements may not represent the average background airflow. These discrepancies propagate through Eqs. (1-3), into the horizontal winds (Weber et al., 1992; Adachi et al., 2005). Cheong et al. (2008) examined the homogeneity across a DBS sampling area, using a coherent imaging radar. They concluded that the assumption of homogeneity was invalid at short (i.e. single-cycle) observation times. Such effects can be reduced with temporal averaging, but this can remove some of the genuine structure in the horizontal flow (Weber et al., 1992), particularly during the passage of fronts (for example, Luce et al. (2001b) showed poor agreement between radiosonde and radar winds measured around a warm front). Inhomogeneity across the sampling area becomes increasingly likely with altitude, as beam separation increases. For example, the horizontal separation between opposing $6^{\circ}$ beams (routinely used by the radar in this study) is $4.2 \mathrm{~km}$ at a range of $20 \mathrm{~km}$. (Where the radar antenna can be steered in a circle, methods like velocity azimuth display and volume velocity processing, e.g. Waldteufel and Corbin, 1979, can be used. The Aberystwyth MST radar, however, can only point to four different azimuths at any given zenith angle, so these approaches cannot be used.)

The uncertainty in winds is also affected by the strength of the signals received by the radar. These decrease with range above the tropopause, and the signal processing algorithm struggles to accurately identify the clear-air signal where the signal-to-noise ratio (SNR) is small (Weber and Wuertz, 1990; Luce et al., 2001b; Srinivasa Rao et al., 2008).

The uncertainties associated with these different contributions are difficult to quantify. Radiosondes are the typical reference instrument, but they sample the wind field in a very different way to a wind profiler, measuring the average wind velocity along short sections of the line of ascent. In contrast, DBS radars combine volume averages over several beams and several minutes. Radiosondes also drift from the launch site, and may not sample the same volume as the radar. Weber and Wuertz (1990) and Srinivasa Rao et al. (2008) compared radiosonde and radar winds, and noted an increase in wind velocity differences with height; however they were unable to separate the potential effects of radiosonde drift.

At VHF, the effects of anisotropic scatter must also be considered, since the strength of backscatter at angles closer to the vertical is usually enhanced (Luce et al., 2001a), causing the effective pointing angle of off-vertical beams to move closer to the zenith. Horizontal winds will be underestimated if the effective pointing angle $\theta_{\text {eff }}$ is not used in Eqs. (1-3). For the Aberystwyth radar, $\theta_{\text {eff }}$ is calculated using the following formula (Hocking et al., 1986):

$\sin \theta_{\mathrm{eff}}=\sin \theta\left[1+\frac{\sin ^{2} \Theta}{\sin ^{2} \vartheta_{\mathrm{s}}}\right]^{-1}$,

where $\theta$ is the intended pointing zenith angle of the beam and $\Theta$ is the beam's two-way $e^{-1}$ half-width. $\vartheta_{\text {s }}$ indicates the degree of aspect sensitivity (Hocking et al., 1986) and is defined as follows (Hooper and Thomas, 1995) using echo powers, $P(\theta)$, from two beams at zenith angles $\theta_{1}$ and $\theta_{2}$ :

$\vartheta_{\mathrm{s}}=\arcsin \sqrt{\frac{\sin ^{2} \theta_{2}-\sin ^{2} \theta_{1}}{\ln \frac{P\left(\theta_{1}\right)}{P\left(\theta_{2}\right)}}-\sin ^{2} \Theta .}$

$\vartheta_{\mathrm{s}}$ approaches zero for specular reflectors, and is around $4-5^{\circ}$ or greater for isotropic scatterers, where vertical beam echo powers are compared with off-vertical measurements (Hocking and Hamza, 1997). Experiments by Hocking et al. (1986) 
with the SOUSY (Sounding System for Atmospheric Structure and Dynamics) radar showed a rapid fall-off of echo power with angles close to the zenith, followed by a slower decrease at larger angles. This implies that different values of $\vartheta_{\text {s }}$ apply at different beam zenith angles. The same result has been found with measurements from the Aberystwyth MST radar (Hooper and Thomas, 1995).

Aspect sensitivity tends to be strongest at the tropopause and in the lower stratosphere (Hocking et al., 1986, 1990; Luce et al., 2001a), though strong aspect sensitivity has been observed throughout the free troposphere during, and after, the passage of synoptic fronts (Hooper and Thomas, 1995; Kawano and Fukao, 2001). It is likely that corrugated sheets of constant refractive index are responsible for the anisotropic echoes typically observed at VHF frequencies (Luce et al., 2001a). Equation (4), however, assumes that sheets are smooth, and some studies suggest that correcting winds for aspect sensitivity may not improve measurements. Hocking et al. (1990) found that corrections for effective pointing angle were not needed to get close agreement between horizontal winds measured at different beam zeniths. Kawano and Fukao (2001) directly measured the arrival angle of echoes under conditions of aspect sensitivity, using spatial interferometry, and found that these were distributed about the intended $10^{\circ}$ pointing angle, rather than biased towards the vertical. We return to this point in Sect. 3 .

Quantifying aspect sensitivity may also be complicated by an azimuthal dependence of echo power. Worthington et al. (1999b) created maps of aspect sensitivity, using both the MU (Middle and Upper Atmosphere) radar in Japan and the NERC MST radar at Aberystwyth (used in this study). They showed that the peak in echo power can be displaced from the zenith, and that displacement direction was correlated with the direction of wind shear. Echo power anisotropy can extend to large off-vertical zenith angles (Worthington et al., 1999a, measuring with the MU and Aberystwyth radars, found aspect sensitivity at zenith angles of 30 and $12^{\circ}$, respectively).

Several studies have sought to quantify the various uncertainties in winds derived from the Aberystwyth MST radar. Thomas et al. (1997) made a comparison with 75 radiosondes launched from Aberporth, $50 \mathrm{~km}$ southwest of the radar site. They concluded that the radar underestimated horizontal wind velocities by 4-5\%, and that aspect sensitivity corrections were necessary to remove the bias. However, they also reported that correction actually degraded the correlation at some altitudes, and had no effect at others, when sonde profiles were considered individually. Hooper et al. (2008) compared Aberystywth radar and radiosonde winds to wind fields from the global run of the Met Office's Unified Model (see also Hooper et al., 2013b). They noted a systematic overestimate of radar wind speeds below $10 \mathrm{~km}$, and an underestimate above; the magnitude of the bias was less than $1 \mathrm{~m} \mathrm{~s}^{-1}$. The root mean square (RMS) difference in consecutive $30 \mathrm{~min}$ averages of horizontal wind speeds showed an increase with altitude, from $2 \mathrm{~m} \mathrm{~s}^{-1}$ at $2 \mathrm{~km}$, to $3 \mathrm{~m} \mathrm{~s}^{-1}$ at $15 \mathrm{~km}$. RMS differences above $15 \mathrm{~km}$ increased significantly, as SNR reduced.

A surprising result from long-term VHF radar measurements is that average vertical velocities are often non-zero. Such profiles have been measured with many different instruments, including the Aberystwyth radar (Worthington et al., 2001). To achieve conservation of mass, mean vertical velocities are expected to be negligible; however typical profiles measured at Aberystwyth show downward motion in the mid-troposphere (peaking at more than $-4 \mathrm{~cm} \mathrm{~s}^{-1}$ ) and upward velocities in the lower stratosphere (peaking at $2 \mathrm{~cm} \mathrm{~s}^{-1}$ ). Worthington et al. (2001) reviewed the potential causes of such measurements, which included persistent vertical velocities observed around jet streams and streaks, false measurements associated with tilted aspect sensitive layers, and false measurements associated with gravity waves. The authors concluded that local mountain waves are the only mechanism capable of explaining all of the cases examined at Aberystwyth. Under such a model, the phases of mountain waves above the radar are not random. This skews long-term averages of vertical velocity towards the dominant mountain wave pattern.

The Aberystwyth MST radar was renovated in March 2011 (Hooper et al., 2013a). This paper re-assesses the uncertainties in its wind velocity measurements, both before and after the renovation, using 127 radiosondes launched from the radar site. This data set is expected to give a more accurate reflection of the uncertainties in radar winds than previous studies, given the proximity of the sondes to the radar. We also re-examine the effects of aspect sensitivity corrections, using 8 weeks of special observations that measured on 17 different beams. The next section introduces the radar and radiosonde measurement techniques, and analysis methods; Sect. 3 discusses the results; and the conclusions are presented in Sect. 4.

\section{Radar and radiosonde measurements}

The NERC MST radar (Table 1) operates at $46.5 \mathrm{MHz}$ and has a phased antenna array which allows 17 possible beam pointing directions: vertical, and 4.2, 6.0, 8.5, and $12.0^{\circ}$ off-vertical. For each non-zero zenith angle, beam pointing directions are available in four azimuths, at $90^{\circ}$ separations.

This study uses measurements made with a vertical resolution of $300 \mathrm{~m}$ and a sampling interval of $150 \mathrm{~m}$. Typically each cycle comprises (i) dwells in all four $6^{\circ}$ off-vertical beam pointing directions, for the derivation of horizontal wind components; (ii) a dwell at $4.2^{\circ}$ off-vertical (towards an azimuth of $252.5^{\circ}$ ), used to derive the effective pointing angle of $6^{\circ}$ off-vertical beams; (iii) a vertical beam dwell covering mesospheric altitudes; and (iv) a vertical dwell covering stratosphere-troposphere altitudes at every second dwell. 
The latter were originally introduced to study rapidly varying vertical velocities associated with convection (Hooper et al., 2005). The measurement time for each dwell is approximately $21 \mathrm{~s}$. There is a gap of a few seconds between each dwell to allow for beam steering. The cycle time before the March 2011 renovation was $4 \mathrm{~min} 55 \mathrm{~s}$. The new beam steering components require longer to switch, resulting in a slightly longer cycle time of 5 min $14 \mathrm{~s}$. This study also uses data from a special observation format that ran for 8 weeks immediately following the renovation. This used all 17 available beam pointing directions, including a vertical beam observation at every third dwell. A single vertical dwell separated complementary $6^{\circ}$ off-vertical dwells. The total cycle time was $11 \min 25 \mathrm{~s}$.

Radial and horizontal wind components are calculated using the radar's routine signal processing software (version 3; Hooper et al., 2008). This uses a variety of self-consistency checks, including for radial and for time continuity, in order to quality-control the data. For each $6^{\circ}$ off-vertical beam, the corresponding horizontal wind component is derived from Eq. (1) using the vertical beam dwell that is closest in time. The off-vertical angle is initially assumed to be $6.0^{\circ}$. The horizontal components for complementary beams are then averaged; however, they are flagged as unreliable if they differ by more than $10 \mathrm{~m} \mathrm{~s}^{-1}$. For each cycle, $\theta_{\text {eff }}$ is derived from Eqs. (4) and (5) using the average signal power from all four $6^{\circ}$ off-vertical dwells and the single $4.2^{\circ}$ off-vertical dwell. A simplified factor of $\sin 6.0 / \sin \theta_{\text {eff }}$ is used to compensate the wind speed for the effective pointing angle. This assumes that variations in $\theta_{\text {eff }}$ do not affect the value of $w \cos \theta$ in Eq. (1). This assumption is justified because $\cos \theta$ varies by only 0.002 between a $\theta_{\text {eff }}$ value of $6.0^{\circ}$ (i.e. zero aspect sensitivity) and one of $4.5^{\circ}$ (a large aspect sensitivity). The averaged $6.0^{\circ}$ beam signal power is occasionally greater than the $4.2^{\circ}$ beam value. Under such conditions a $\vartheta_{\mathrm{s}}$ of $90^{\circ}$, representing perfectly isotropic scatter, is assumed. The wind speed compensation factor is clamped to a maximum value of 1.5 for highly anisotropic scatter, corresponding to a $\theta_{\text {eff }}$ of $4.0^{\circ}$.

Radiosonde winds are taken from 127 Vaisala RS92G flights launched from the Aberystwyth radar site between March 2008 and January 2012. Winds are calculated from the position of the sonde, measured using the instrument's GPS receiver. The standard error in radiosonde wind components is less than $0.5 \mathrm{~m} \mathrm{~s}^{-1}$ (Nash et al., 2011). Radiosonde winds are averaged over $300 \mathrm{~m}$ height intervals, corresponding to the radar's pulse length, and are used to calculate the systematic difference between radar and radiosonde horizontal winds.

Radial velocities from opposing beams can be combined to give vertical velocity ( $w_{\mathrm{c}}$, Eq. 6), assuming homogeneity of the wind field across the beams. The difference with directly measured vertical velocities ( $w_{\mathrm{d}}$, from the vertical beam) gives a measure of the random errors in radar winds that arise from inhomogeneity across the beams (Eq. 7, where
$\left.\Delta w=w_{\mathrm{d}}-w_{\mathrm{c}}\right)$.

$w_{\mathrm{c}}=\frac{V_{r}(\phi)+V_{r}(\phi+180)}{2 \cos \theta}$
$\mathrm{RMS}=\sqrt{\frac{1}{N} \sum_{i=1}^{N}\left(\Delta w_{i}\right)^{2}}$

Where beams with different zenith angles are compared in this study, velocities and echo powers have been linearly interpolated to the range gates of the $6^{\circ}$ zenith beams, to account for differences in sampling altitudes.

\section{Results and discussion}

\subsection{Biases}

The impact of the radar renovation is illustrated in Fig. 1, which shows the systematic difference between radiosonde and MST radar horizontal wind speed. Before renovation, the radar underestimated horizontal wind speed at nearly all altitudes (Fig. 1a). Post-renovation speeds, corrected for aspect sensitivity, show no overall difference (Fig. 1d), but wind speed is overestimated below $10 \mathrm{~km}$ and underestimated above (Fig. 1b). The post-renovation profile has the same pattern as that presented by Hooper et al. (2008), who calculated mean wind speed differences between V3 winds and the Met Office Global Model, between July 2006 and January 2007. The origin of this altitude dependence is discussed shortly.

Systematic differences in pre-renovation winds are similarly observed when radial velocities are compared. For example, Fig. 2 compares vertical velocities derived from complementary and vertical beams, where the wind direction was within $45^{\circ}$ of the north-east beam azimuth angle $\left(27.5^{\circ}\right)$; one year of measurements are used pre- and post-renovation (2010 and 2012, respectively). There is no systematic difference in post-renovation winds (except possibly at very high wind speeds where sampling statistics are poor - Fig. $2 \mathrm{~b}$ and d), but pre-renovation differences vary with wind speed and the complementary beam pair used. However, when winds are directed along the orthogonal beam pair (NW-SE direction, not shown) a different pattern emerges: the NE-SW beams show no bias, and the NW-SE profiles are negative but do not change with wind speed. This unpredictable pattern suggests a problem with beam formation, affecting all beams (such a fault is discussed by Hooper et al., 2013b). The biases disappear after the renovation, suggesting that a fault with beam steering prevented proper phasing of the antennas in the array. The similarity between our post-renovation wind speed differences (Fig. 1b) and those presented by Hooper et al. (2008) suggests that the beam steering fault developed after January 2007 (the end date of the Hooper et al., this study). 

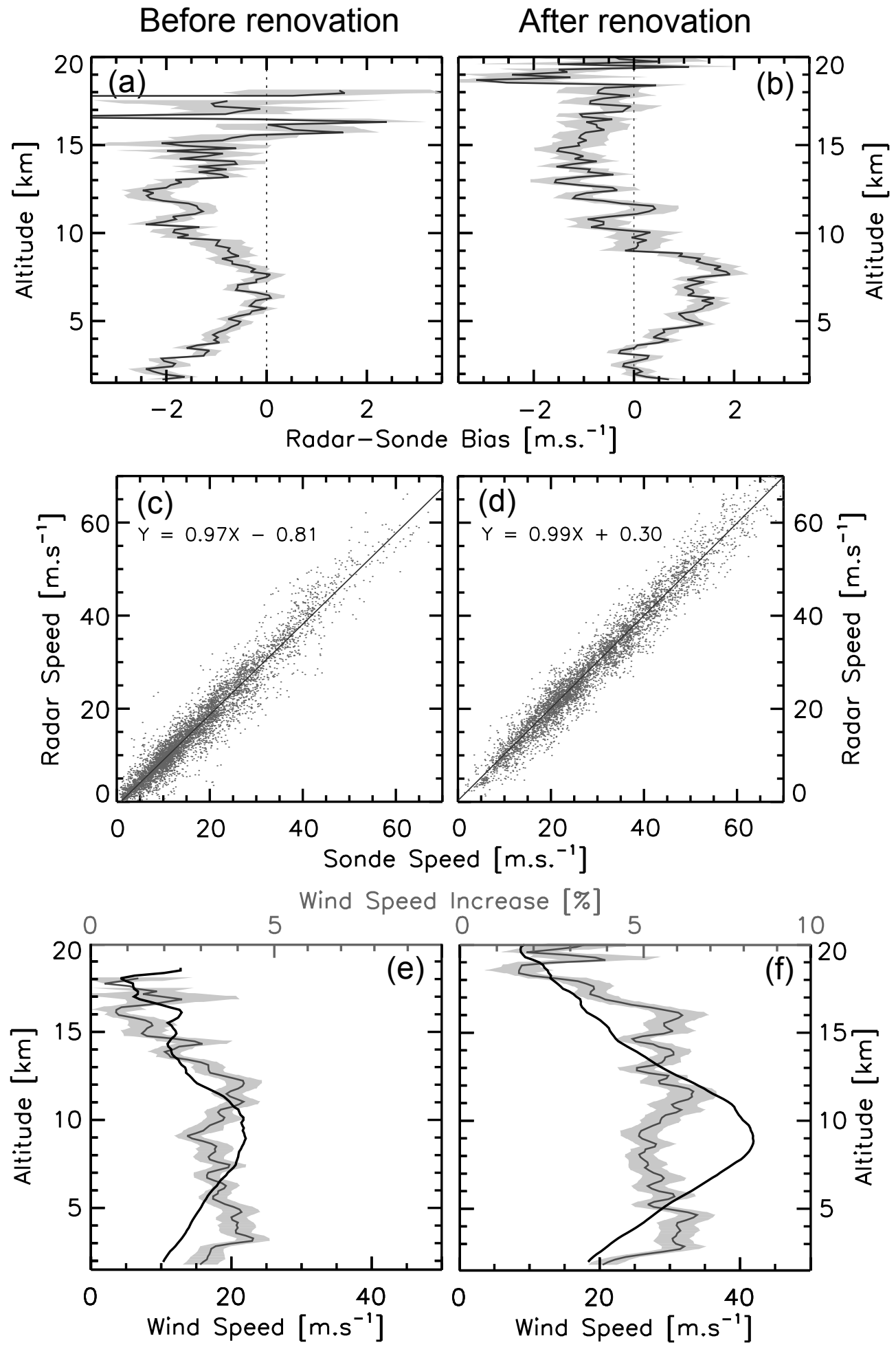

Figure 1. Comparison of wind speeds measured by the MST radar, and 75 and 52 radiosonde launched from the Aberystwyth radar site, preand post-renovation, respectively. (a) Average radar-radiosonde wind speed differences at different altitudes, before the renovation. Negative differences correspond to radar speeds smaller than radiosonde speeds. The grey shading shows the standard error. Radar winds have been corrected for aspect sensitivity. (b) As (a) but after the renovation. (c) MST against radiosonde wind speeds at all altitudes. The grey line is a best fit, quantified by the text at the top of the panel. (d) As (c) but after renovation. (e) Average MST radar wind speed (bottom axis and black line) and aspect sensitivity correction (top axis and grey line, with shading giving standard error) for the pre-renovation comparison. (f) As (e) but after renovation. 

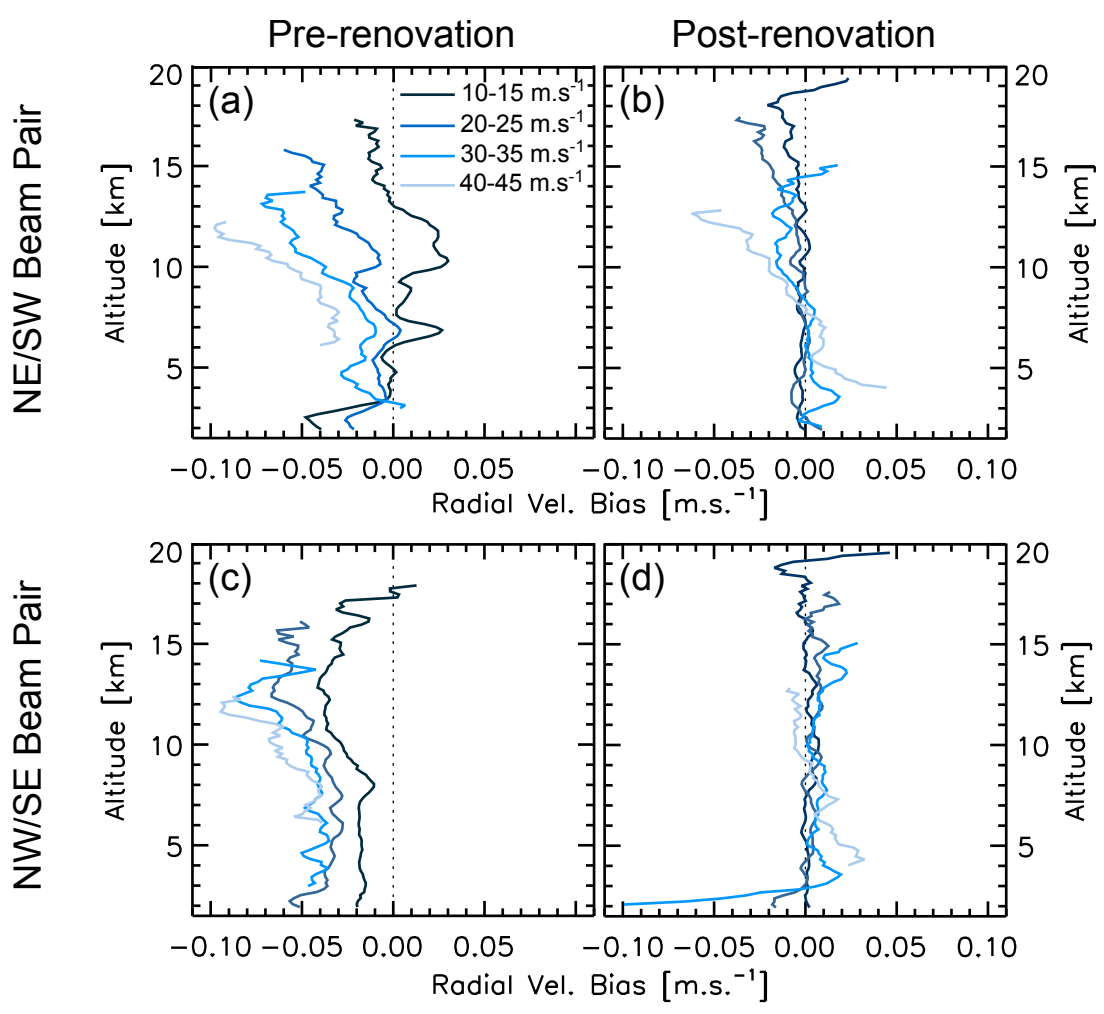

Figure 2. Vertical velocity bias at different wind speeds before and after the renovation. Biases are derived from comparison of vertical beam vertical velocities and the difference of complementary beam radial velocities (Eq. 6). Different shaded curves correspond to different horizontal wind speeds. The curves comprise all valid winds where the mean wind direction was within $45^{\circ}$ of the NE beam azimuth $\left(27.5^{\circ}\right)$, during 2010 (pre-renovation) and 2012 (post-renovation). Negative biases correspond to an underestimate of vertical velocity by the complementary beam pair. (a) Pre-renovation biases from the NE-SW beam pair. (b) As (a) but post-renovation. (c) As (a) but for NW-SE beam pair. (d) As (b) but for NW-SE beam pair.

There is a striking anti-correlation between radarradiosonde wind speed differences (post-renovation) and vertical velocities measured by the radar (Fig. 3). This suggests that horizontal winds above the radar are influenced by mountain waves: because radiosondes drift from the radar site (shown by the flight tracks in Fig. 4), they measure a different phase of the mountain waves, thus introducing the horizontal wind speed differences in Fig. 3a.

The pattern of mountain waves, and hence average vertical velocities, is expected to change with wind direction, because the terrain around Aberystwyth is inhomogeneous. Figure 5a shows average vertical velocity profiles from 30 months of measurements, binned according to the $2 \mathrm{~km}$ wind direction. ( $2 \mathrm{~km}$ winds have been chosen as a measure of low-level winds that could drive mountain waves; Worthington, 1999.) Westerly winds occur $49 \%$ of the time (approximately 617000 profiles), with an average vertical velocity profile like that of the special operation period. (Note that westerlies dominate the special operation period and radarsonde comparisons.) Southerly (24\% - 299000 profiles) and northerly (18\%-223 000 profiles) winds are associated with smaller average vertical velocities, with magnitudes roughly half those of the westerly profile. Finally, average vertical velocities during easterly winds ( $9 \%-119000$ profiles) are around half the strength of the westerly profile below $10 \mathrm{~km}$, but tend to zero above. The tendency towards zero can be explained by changes in winds with height. Figure $5 \mathrm{~b}$ shows that easterly winds at the surface persist up to an altitude of $8 \mathrm{~km}$, and then gradually back to northerlies over the next $5 \mathrm{~km}$; there then follows a sharp backing to westerlies over less than a kilometre. This backing through $180^{\circ}$ is a critical layer, through which the mountain waves cannot propagate, hence the near-zero vertical velocities above $10 \mathrm{~km}$. Pavelin and Whiteway (2002) presented a case study of such critical level filtering above the Aberystwyth radar site.

Finally, further evidence of mountain wave activity is shown by the change in the average vertical velocity profile with wind speed. Figure 6 shows the westerly vertical velocity profile (from Fig. 5a) decomposed according to $2 \mathrm{~km}$ wind speeds. Where horizontal speeds are low (5$10 \mathrm{~m} \mathrm{~s}^{-1}$ ), average vertical velocities are a few centimetres per second; but these grow, and the peaks change altitude, as wind speeds increase. Average vertical velocities become very large (exceeding $0.5 \mathrm{~m} \mathrm{~s}^{-1}$ below $5 \mathrm{~km}$ ) when horizon- 


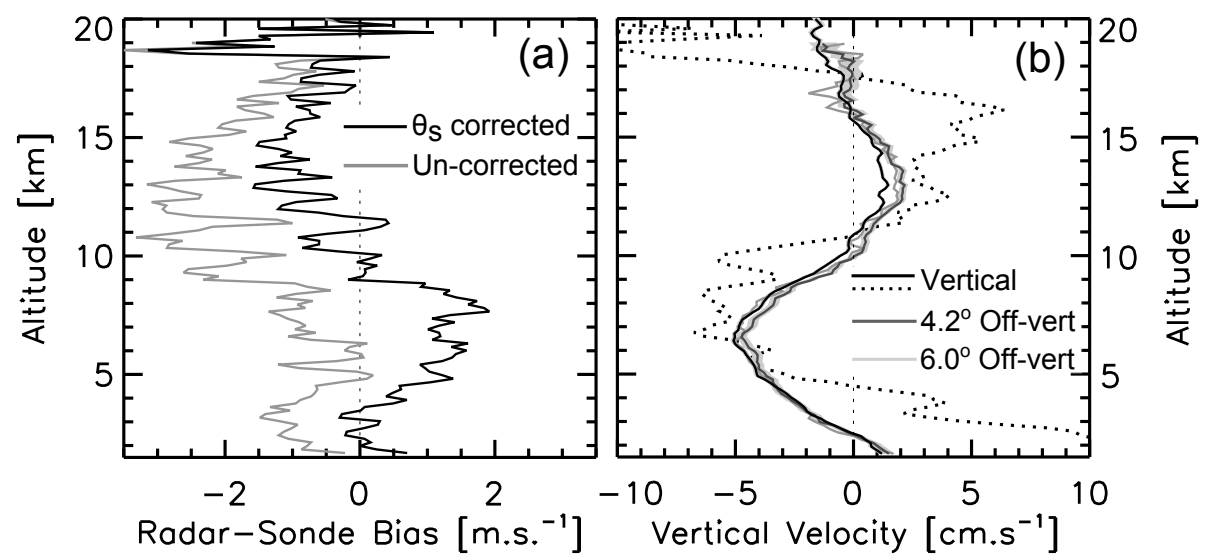

Figure 3. (a) As Fig. 1b but showing radar-radiosonde wind speed bias corrected for aspect sensitivity (black line) and un-corrected (grey line). Error shading has not been included to aid interpretation; the standard error for both curves is as Fig. 1b. (b) Dotted line: vertical velocities from the vertical beam averaged over the radar-radiosonde comparison period. The standard error (not shown) is the width of the solid lines. Solid lines: vertical velocities averaged over the 8 weeks of special operation, from vertical, and complementary off-vertical (4.2 and $6^{\circ}$ degree zenith), beams. Shading shows the standard error for the vertical and $4.2^{\circ}$ beams. To aid interpretation, the error for the $6^{\circ}$ beam is omitted, but it is comparable to that of the $4.2^{\circ}$ beam.

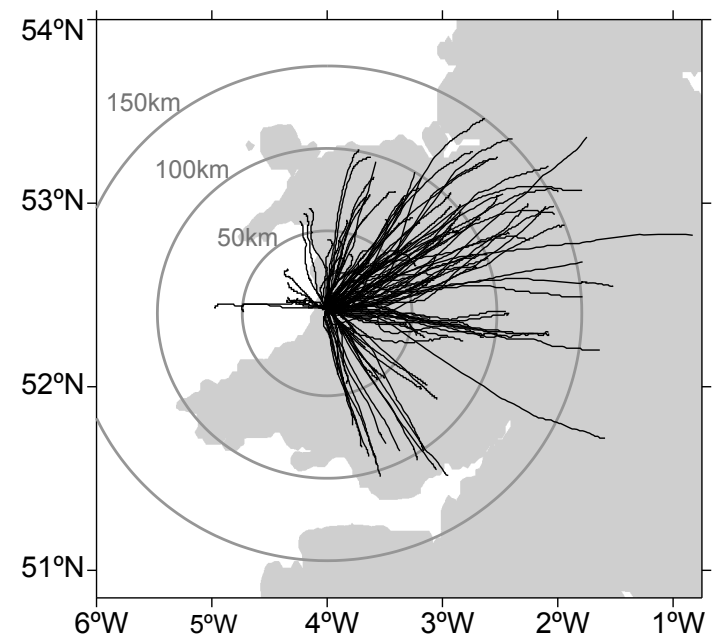

Figure 4. Flight tracks of 127 radiosondes launched from the Aberystwyth radar site. The grey shading indicates the land surface, and $50 \mathrm{~km}$ range intervals are shown by the concentric grey circles centred on the radar site. Only the first $21 \mathrm{~km}$ of sonde ascent are shown, corresponding to the upper altitude limit of the MST radar.

tal speeds are $35-40 \mathrm{~m} \mathrm{~s}^{-1}$. Westerlies with those speeds are observed $0.02 \%$ of the time (248 profiles in the 30-month period); $5-10 \mathrm{~m} \mathrm{~s}^{-1}$ westerlies at $2 \mathrm{~km}$ occur $15 \%$ of the time (approximately 186000 profiles).

The profiles in Figs. 5 and 6 are averages over 30 months, and the patterns for individual cases will depend on the exact wind direction, wind speed, and stability of the atmosphere. Attempting to decompose such effects, and assessing their impact on horizontal winds, is beyond the scope of this study; however, it is clear that the accuracy of horizontal wind mea- surements depends on local conditions, particularly low-level wind speed and direction.

\subsection{Aspect sensitivity corrections}

Routine wind profiling with the Aberystwyth radar uses only one $4.2^{\circ}$ zenith beam to calculate aspect sensitivity. Azimuthal anisotropy of echo power therefore has the potential to introduce discrepancies into corrections. Average power maps at $2.5 \mathrm{~km}$ height intervals, derived from the special operation measurements, are shown in Fig. 7. At most altitudes the echo power is largely azimuthally isotropic, though $7.5 \mathrm{~km}$ echo powers are skewed towards larger zeniths in the south-west direction (the star symbol in each map indicates the $4.2^{\circ}$ beam used for aspect sensitivity calculations). Effective pointing angles derived from the average power maps using one and four $4.2^{\circ}$ beams are similar (Fig. 8a). In contrast, there are significant differences between the one- and fourbeam approaches when echo powers are averaged over only $1 \mathrm{~h}$ (Fig. 9); at these timescales the single $4.2^{\circ}$ beam measurements are not representative of the average echo power, because of azimuthal anisotropy. Routine aspect sensitivity correction uses only one beam, and so introduces this random error into corrected horizontal winds. (Note that these one-hour averages span six cycles of measurements - the same number as a half-hour average during the routine observations used in previous sections.) The RMS difference between the effective pointing angles derived from one, and all four, $4.2^{\circ}$ beams is shown in Fig. 8 b, for the period of special operation. The corresponding uncertainty in horizontal wind components (top axis in Fig. 8b) is around 3.5\% above $8 \mathrm{~km}$, but is as large as $4.5 \%$ in the mid-troposphere. 


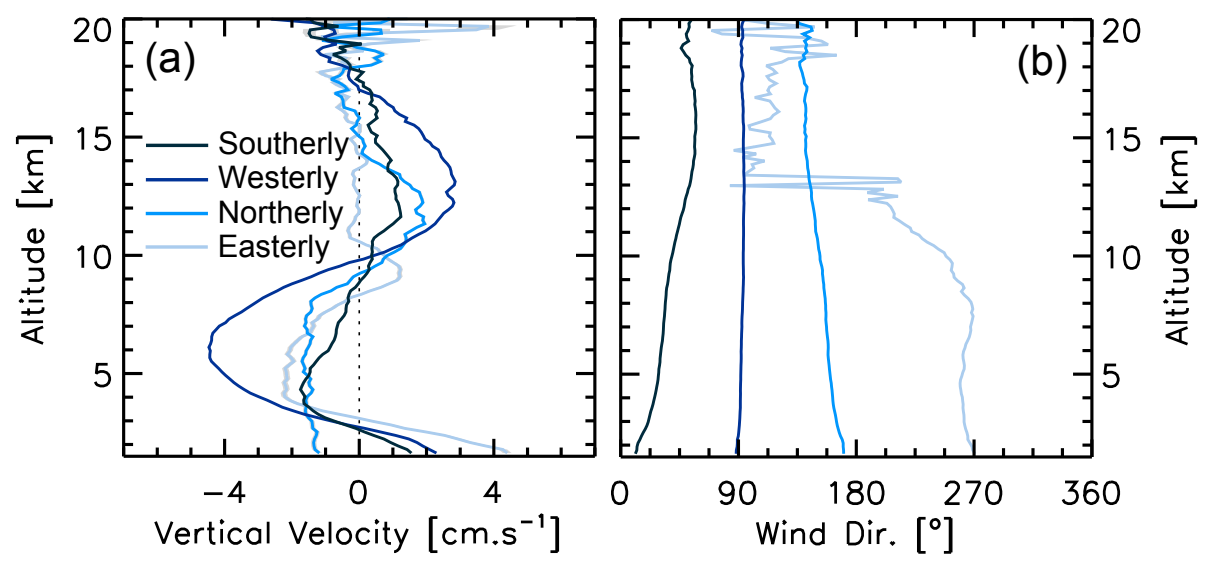

Figure 5. (a) Mean vertical velocities for different $2 \mathrm{~km}$ wind directions. 30 months of data from May 2011 have been used. The four curves comprise measurements whose $2 \mathrm{~km}$ wind vectors are within $45^{\circ}$ of north, south, east and west (indicated in the legend as southerlies, northerlies, westerlies, and easterlies, respectively). Shading gives the standard error, which is often smaller than the line thickness. (b) Mean wind direction in the profile when the direction at $2 \mathrm{~km}$ lies in one of the four quadrants.

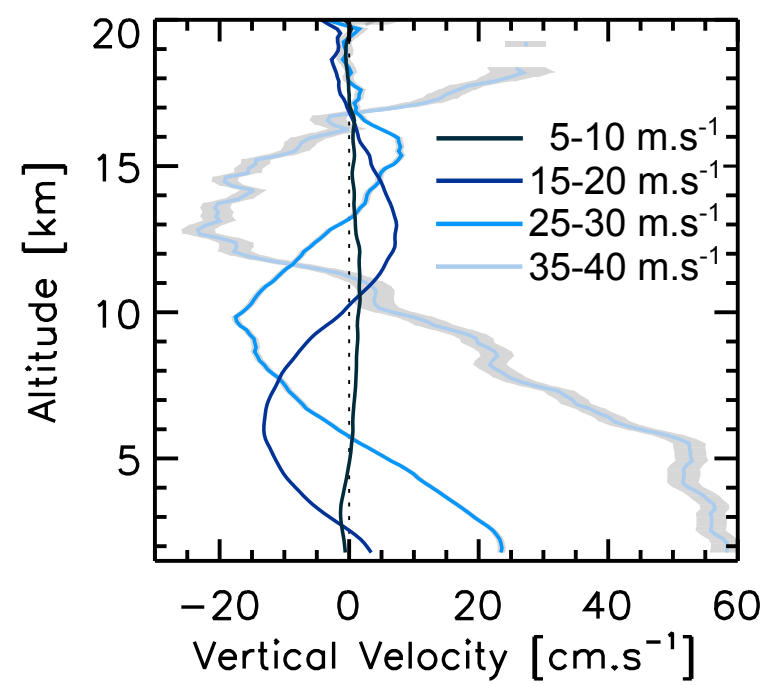

Figure 6. As Fig. 5a but showing the $2 \mathrm{~km}$ westerly winds, decomposed into different $2 \mathrm{~km}$ wind speeds (shown by the legend).

\subsection{Root mean square errors}

The random error in radial wind measurements is assessed by comparing vertical and complementary beam observations (Eq. 7). Radar-sonde comparisons cannot be used because sondes drift from the radar site (Fig. 4) and do not sample the local conditions above the radar.

The RMS difference of complementary beam radial winds increases with both wind speed and altitude (Fig. 10, which shows the root mean square error - RMSE - corresponding to a single beam, $V_{\mathrm{r}}$, in Eq. 6). The altitude dependence is related to the radar's signal-to-noise ratio, as well as the greater horizontal separation of the beams with height. At low SNR, the probability of detecting the clear-air signals is reduced, so the number of reliable beam pairs decreases toward the top of the profile. (The definition of SNR used in this study is the ratio of peak signal power spectral density to noise.) The marked improvement in post-renovation SNR (around $5 \mathrm{~dB}$ below $13 \mathrm{~km}$ and $2-4 \mathrm{~dB}$ above; Fig. 11) provides more occasions where measurements from both beams in a pair are available to calculate the RMS differences in Fig. 10.

The increase in horizontal wind component RMSEs with wind speed is approximately linear for the speeds examined here. Figure 12 shows a combination of the the uncertainties introduced by aspect sensitivity corrections (discussed in the previous section, and shown in Fig. 8b), and horizontal wind component uncertainties corresponding to the radial velocity errors shown in Fig. 10 (top axis). A $10 \mathrm{~m} \mathrm{~s}^{-1}$ increase in wind speed corresponds to a $0.5 \mathrm{~m} \mathrm{~s}^{-1}$ increase in horizontal component RMSE. Random errors also increase with altitude; post-renovation they grow from $0.8 \mathrm{~m} \mathrm{~s}^{-1}$ (around $6.5 \%$ of the wind speed) to more than $1.5 \mathrm{~m} \mathrm{~s}^{-1}$ (>12\%) between $5 \mathrm{~km}$ and the top of the radar's altitude range, under low wind speeds $\left(10-15 \mathrm{~m} \mathrm{~s}^{-1}\right)$. At high wind speeds (40-45 $\mathrm{m} \mathrm{s}^{-1}$ ), RMSEs are larger than $2.5 \mathrm{~m} \mathrm{~s}^{-1}$ at upper altitudes. Error profiles before renovation are around $0.1 \mathrm{~m} \mathrm{~s}^{-1}$ larger than post-renovation values. For practical application an approximation to these profiles is given by the dashed lines in Fig. 12, and is quantified in Appendix A. (Note that Fig. 12a shows RMSEs for 2009, rather than 2010 as in Fig. 10a. The 2009 results are more consistent with those from previous years, because of the continued degradation of the beam steering units in 2010. Consequently we have used 2009 results to calculate the error profile approximations.)

Hooper et al. (2008) presented RMS difference profiles of radar and model winds which show the same trends presented here; however the magnitude of their differences are much larger. This is attributed to the comparison method: the model comparison includes any systematic differences between the radar and the model, as well as differences between 

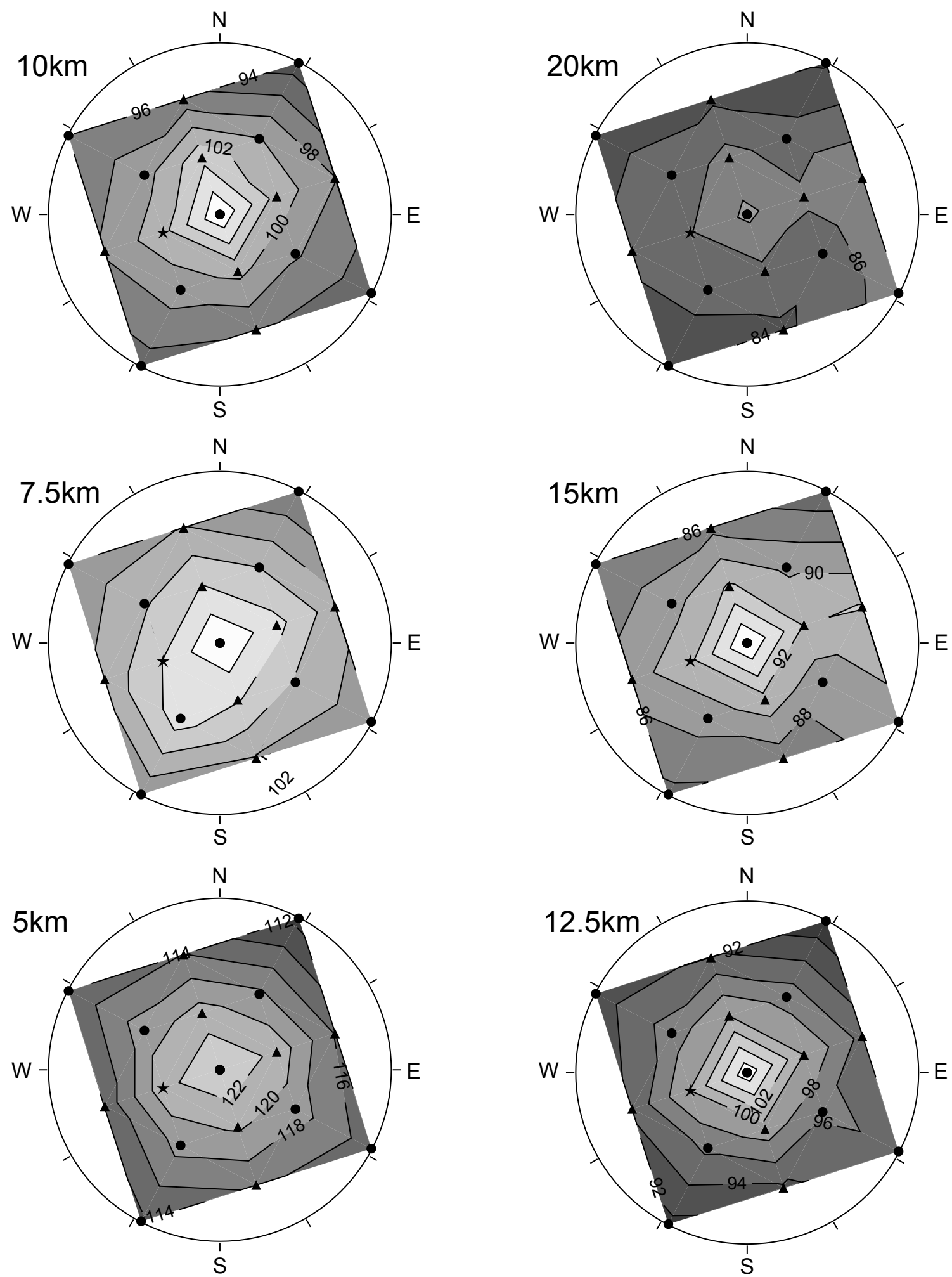

Figure 7. Average echo power maps derived from 8 weeks of special operation. The contours and labels give echo power in decibels. Symbols indicate the location of beams. Circles correspond to the 0,6 , and $12^{\circ}$ zeniths; triangles give 4.2 and $8.5^{\circ}$ zeniths. The star indicates the $4.2^{\circ}$ zenith beam used to calculate aspect sensitivity for routine observations. The range is indicated in each panel. 


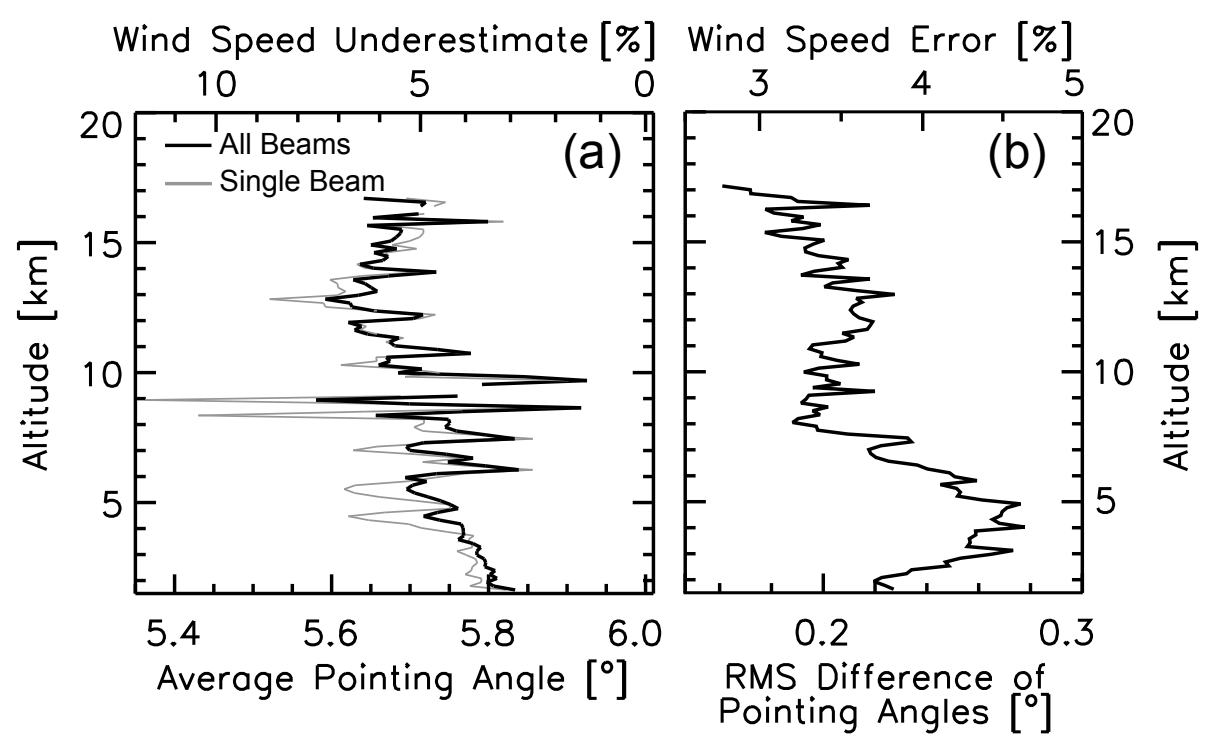

Figure 8. (a) Average effective pointing angles for $6^{\circ}$ beams, calculated across the 8 weeks of special operation. Effective pointing angles using one (grey curve), and all (black curve), $4.2^{\circ}$ beams are shown. The top axis gives the corresponding underestimate in wind speed. (b) RMS difference in effective pointing angles derived using one and four $4.2^{\circ}$ beam echo powers, calculated over the 8 weeks. The top axis gives the corresponding uncertainty in winds corrected with the one-beam method.

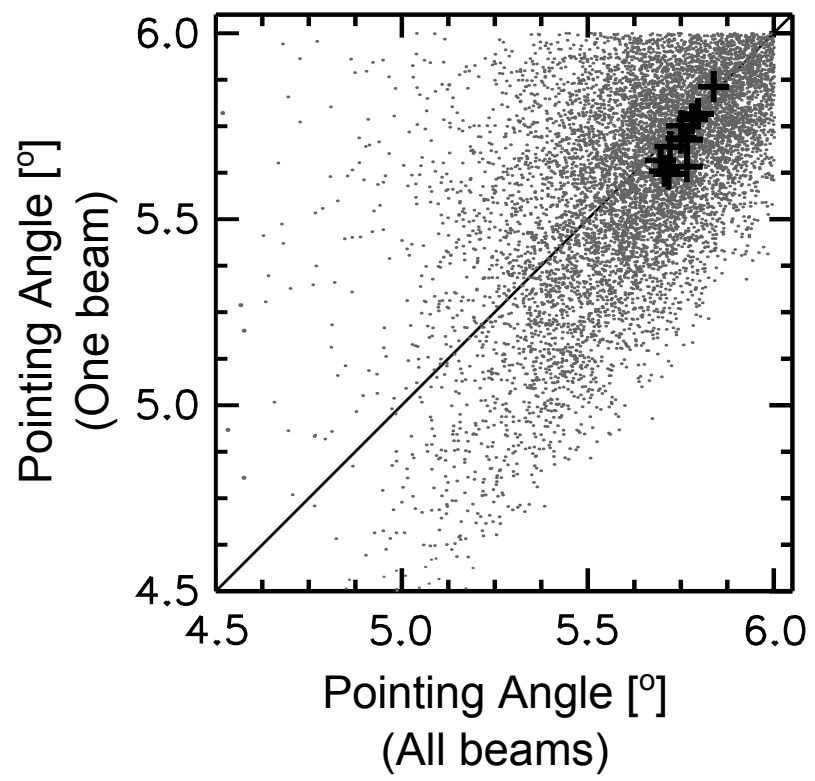

Figure 9. Effective pointing angles derived from 8 weeks of special radar operation, using all $4.2^{\circ}$ zenith beams ( $x$ axis), and the $252.5^{\circ}$ azimuth $4.2^{\circ}$ beam ( $y$ axis). The grey dots are pointing angles from hourly averages, and the pluses are averages over the whole 8 weeks of operation. The solid line traces the $1: 1$ points. Only results for every third height gate between 4 and $9 \mathrm{~km}$ are shown, to aid interpretation.

the (effective) spatial resolution of the two techniques, and the local effects identified in the previous section. Hooper et al. also calculated RMS differences between consecutive
30 min averages of horizontal winds. That comparison includes any temporal changes in the background wind. In contrast our approach effectively quantifies the level of consistency between winds measured on opposing beams, removing sampling effects from different instruments and contributions from scales larger than those of interest.

\section{Conclusions}

We have examined the uncertainties in winds quantified by the NERC MST radar, before and after its renovation in March 2011. The radar underestimates wind speed at almost all altitudes before the renovation, and there is a complex pattern of biases in radial winds that suggests a problem with beam formation (generating unintended pointing angles). After renovation there is no overall bias. The upgrade improved the altitude coverage of the radar, and random errors in wind velocities decreased.

Long-term patterns in vertical velocities are shown to be strongly correlated with radar-radiosonde differences. Our results support the conclusions of Worthington et al. (2001), that the radar is sampling local mountain waves. This is an important consideration when using radar winds as a measure of regional conditions, particularly when assimilating winds for numerical weather prediction. Many other VHF radars record non-zero vertical velocities over long time periods. The horizontal wind effects recorded here may extend to those instruments too.

Altitude and wind speed both affect the random error in wind velocities. Post-renovation horizontal wind 


\section{Pre-renovation Post-renovation}

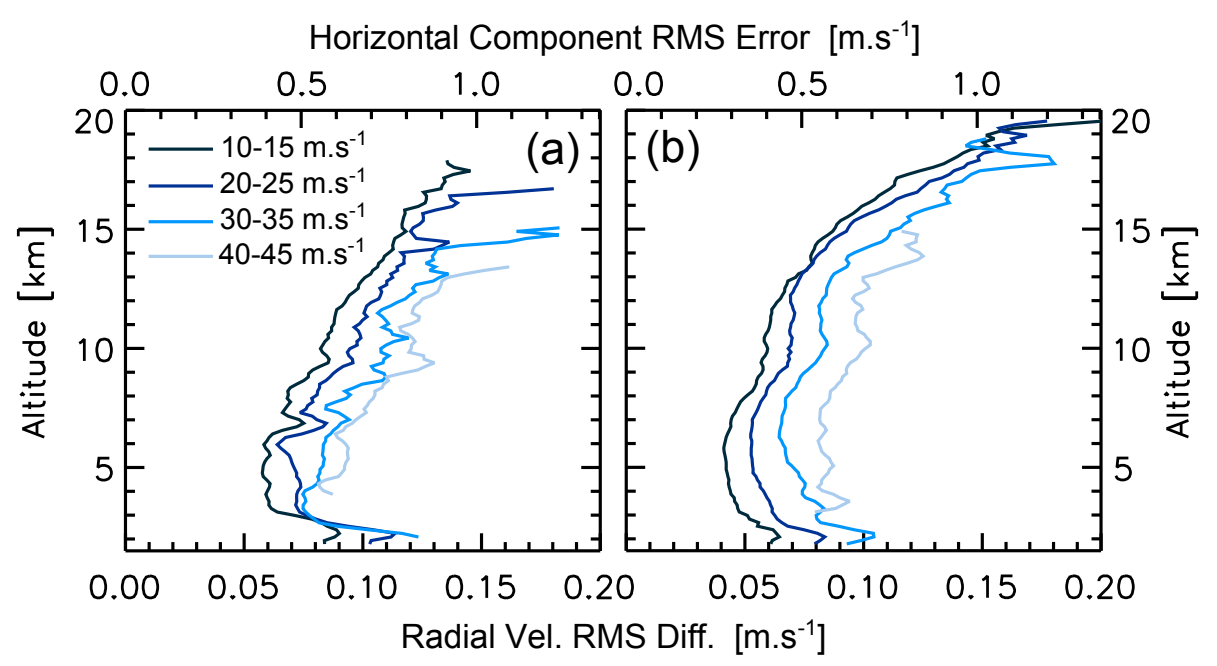

Figure 10. Radial velocity RMS differences at different horizontal wind speeds, before and after the renovation (panels (a) and (b), respectively). RMS values are from the difference of vertical beam and complementary beam vertical velocities, normalised to indicate the error associated with measurements made on a single beam (see text). Different shaded curves correspond to the different horizontal wind speeds described in the legend. The curves are averages of both $6^{\circ}$ zenith beam pairs. Pre-renovation and post-renovation curves use all wind directions in 2010 and 2012, respectively. The top axis gives the corresponding RMSE in horizontal wind components.

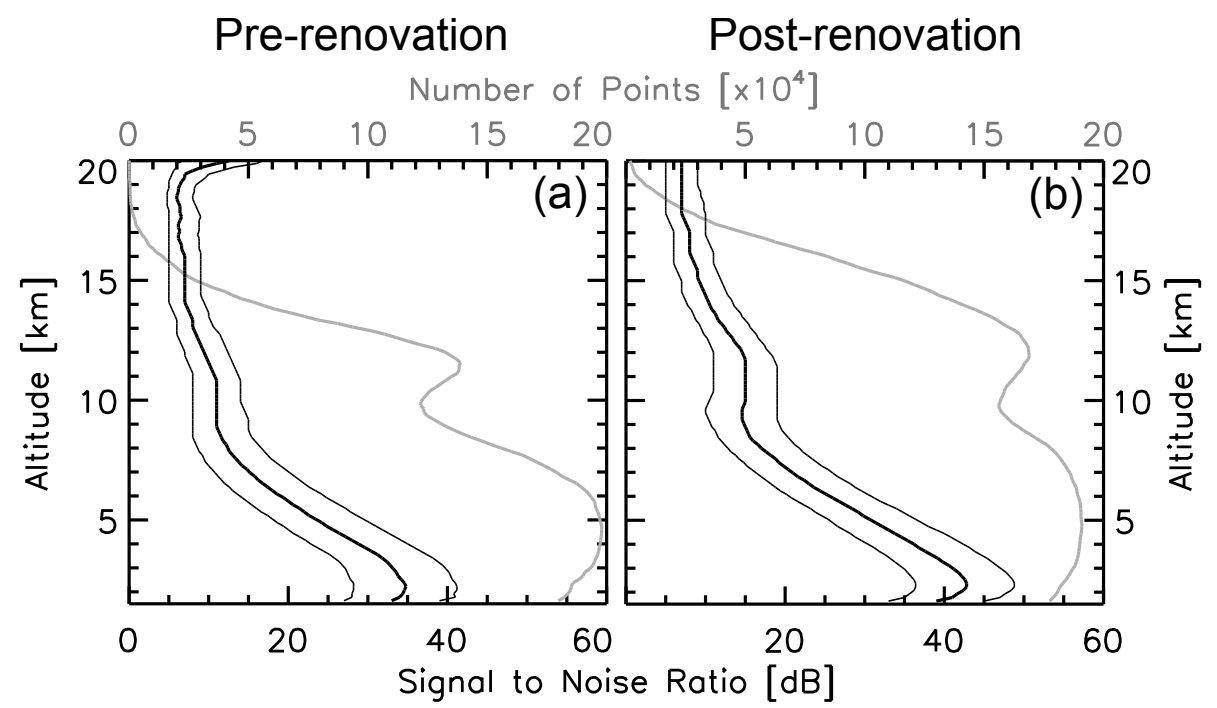

Figure 11. Average SNR (black curves) and the number of reliable ( $6^{\circ}$ zenith angle) complementary beam pairs of measurements (grey curves), before and after renovation (panels a and $b$, respectively). The thin black lines correspond to the upper and lower quartile of the SNR distribution. SNR values shown here are peak signal power spectral density to noise. A whole year of measurements has been used for each figure (2010 and 2012, respectively).

components have RMSEs ranging from $0.8 \mathrm{~m} \mathrm{~s}^{-1}$ in low wind speeds $\left(10-15 \mathrm{~m} \mathrm{~s}^{-1}\right)$ and at low altitudes (below $5 \mathrm{~km}$ ), to greater than $2.5 \mathrm{~m} \mathrm{~s}^{-1}$ at upper altitudes in high winds $\left(40-45 \mathrm{~m} \mathrm{~s}^{-1}\right)$. Faced with such a range, the practice of quoting a single value for wind velocity uncertainty is clearly inadequate. Where the radar is used as a measure of regional winds, the systematic differences identified by the radiosonde comparison, and quantified by Hooper et al. (2008), will also be significant. The random RMSE in radial winds is $<0.04 \mathrm{~m} \mathrm{~s}^{-1}$.

Aspect sensitivity corrections remove the overall bias in horizontal winds, but also contribute to the random error. The mean correction for $6^{\circ}$ zenith angle beams is largely constant with height throughout the troposphere and lowermost stratosphere (up to $15 \mathrm{~km}$ ), and corresponds to a horizontal wind speed increase of 5-6\%. At the timescales 


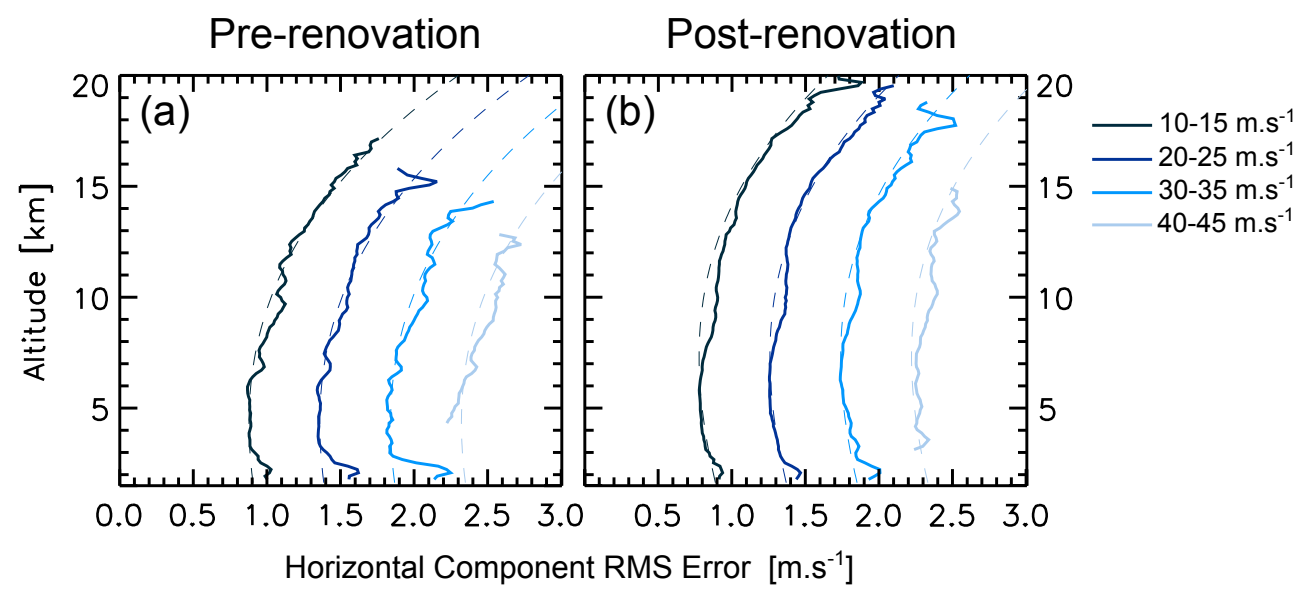

Figure 12. RMSE in horizontal wind components at different horizontal wind speeds. Curves show the combined error from beam separation (Fig. 10), and aspect sensitivity corrections (Fig. 8b) before and after the renovation (panels (a) and (b), respectively). Different shaded curves correspond to the different horizontal wind speeds described in the legend. Pre-renovation and post-renovation curves use all wind directions in 2009 and 2012, respectively. The dashed lines are approximations of the solid lines, calculated with Eq. (A1a) in the Appendix.

used for routine wind profiling $(\approx 1 \mathrm{~h})$, aspect sensitivity is azimuthally anisotropic. Routine wind profiling uses fewer beams than the special operation period examined in this study. This introduces uncertainty into aspect-sensitivitycorrected winds, caused by azimuthal anisotropy of echo powers, and is equivalent to $3.5 \%$ of wind speed in the lower stratosphere and troposphere, and up to $4.5 \%$ in the free troposphere. 


\section{Appendix A: An approximation of standard error in NERC MST radar winds}

Here we present a simple formula to approximate the random errors in horizontal wind components. RMSEs arising from the separation of the off-vertical beams (presented in Sect. 3.3), and beam pointing angle corrections for aspect sensitivity (Sect. 3.2) are considered together. A cubic least squares fit to each RMS profile in Fig. 12 has been made. The shape of the fits vary with year and wind speed. A single curve shape is used to approximate all of the error profiles; it is expressed by Eq. (A1a) and constants a-c in Table A1. $x$ corresponds to the height $(h)$ of observations in kilometres (Eq. A1b); the height offset $\left(h_{\text {off }}\right)$ is an adjustment to account for the step change in errors following the renovation. Changes in random errors with wind speed $(U)$ are implemented by Eq. (A1c); $g_{\text {off }}$ is another offset to account for the pre/post-renovation step change. The final term in Eq. (A1c) corresponds to the error arising from aspect sensitivity corrections, and is approximated as $4 \%$ of wind speed. Variables and constants are summarised in Table A1. Equation (A1a) is plotted with the corresponding RMSE profiles in Fig. 12.

$$
\begin{aligned}
E(x) & =a x^{3}+b x^{2}+c x+d \\
x & =h+h_{\mathrm{off}} \\
d & =g+U f+g_{\mathrm{off}}+0.04 U
\end{aligned}
$$

Table A1. Variables and constants used to approximate the random error in NERC MST radar horizontal winds with Eqs. (A1a-c).

\begin{tabular}{cl}
\hline E & $\begin{array}{l}\text { Standard error in horizontal } \\
\text { winds }\left(\mathrm{m} \mathrm{s}^{-1}\right)\end{array}$ \\
\hline $\mathrm{h}$ & Observation height $(\mathrm{km})$ \\
$\mathrm{U}$ & Wind speed $\left(\mathrm{m} \mathrm{s}^{-1}\right)$ \\
$\mathrm{a}$ & $1.10 \times 10^{-4}$ \\
$\mathrm{~b}$ & $1.64 \times 10^{-3}$ \\
$\mathrm{c}$ & $-4.17 \times 10^{-2}$ \\
$\mathrm{f}$ & $8.10 \times 10^{-3}$ \\
$\mathrm{~g}$ & $3.70 \times 10^{-1}$ \\
$h_{\text {off }}$ & Pre-renovation: 1.5 \\
& Post-renovation: 0 \\
$g_{\text {off }}$ & Pre-renovation: $1.02 \times 10^{-1}$ \\
& Post-renovation: 0
\end{tabular}


Acknowledgements. The Aberystwyth MST radar is funded by the Natural Environment Research Council, with data supplied through the British Atmospheric Data Centre.

Edited by: M. Rapp

\section{References}

Adachi, A., Kobayashi, T., Gage, K. S., Carter, D. A., Hartten, L. M., Clark, W. L., and Fukuda, M.: Evaluation of threebeam and four-beam profiler wind measurement techniques using a five-beam wind profiler and collocated meteorological tower, J. Atmos. Ocean. Tech., 22, 1167-1180, 2005.

Cheong, B. L., Yu, T. Y., Palmer, R. D., Yang, K. F., Hoffman, M. W., Frasier, S. J., and Lopez-Dekker, F. J.: Effects of wind field inhomogeneities on Doppler beam swinging revealed by an imaging radar, J. Atmos. Ocean. Tech., 25, 1414-1422, 2008.

Hocking, W. K. and Hamza, A. M.: A quantitative measure of the degree of anisotropy of turbulence in terms of atmospheric parameters, with particular relevance to radar studies, J. Atmos. Terr. Phys., 59, 1011-1020, 1997.

Hocking, W. K., Rüster, R., and Czechowsky, P.: Absolute reflectivities and aspect sensitivities of VHF radiowave scatterers measured with the SOUSY radar, J. Sol.-Atmos. Terr. Phys., 48, 131144, 1986.

Hocking, W. K., Fukao, S., Tsuda, T., Yamamoto, M., Sato, T., and Kato, S.: Aspect sensitivity of stratospheric VHF radio-wave scatterers, particularly above $15 \mathrm{~km}$ altitude, Radio Sci., 25, 613627, 1990.

Hooper, D. and Thomas, L.: Aspect sensitivity of VHF scatterers in the troposphere and stratosphere from comparisons of powers in off-vertical beams, J. Atmos. Terr. Phys., 57, 655-663, 1995.

Hooper, D. A., McDonald, A. J., Pavelin, E., Carey-Smith, T. K., and Pascoe, C. L.: The signature of mid-latitude convection observed by VHF wind-profiling radar, Geophys. Res. Lett., 32, 334-337, 2005.

Hooper, D. A., Nash, J., Oakley, T., and Turp, M.: Validation of a new signal processing scheme for the MST radar at Aberystwyth, Ann. Geophys.-Italy, 26, 3253-3268, 2008.

Hooper, D. A., Bradford, J., Dean, L., Eastment, J. D., Hess, M., Hibbett, E., Jacobs, J., and Mayo, R.: Renovation of the Aberystwyth MST radar: evaluation, in: Proceedings of the Thirteenth International Workshop on Technical and Scientific Aspects of MST Radar, Leibniz-Institute of Atmospheric Physics at the Rostock University, Kühlungsborn, Germany, 86-90, 2013a.

Hooper, D. A., Edwards, D. M., Holmes, G., Linklater, K., Oakley, T., Parrett, C., and Turp, M.: The usefulness of modelcomparison statistics for wind-profiling radar operators, in: Proceedings of the Thirteenth International Workshop on Technical and Scientific Aspects of MST Radar, 141-150, Leibniz-Institute of Atmospheric Physics at the Rostock University, Kühlungsborn, Germany, 2013b.
Kawano, N. and Fukao, S.: Investigation on horizontal wind estimation around high aspect sensitivity, Radio Sci., 36, 1477-1492, 2001.

Luce, H., Crochet, M., and Dalaudier, E.: Temperature sheets and aspect sensitive radar echoes, Ann. Geophys., 19, 899-920, 2001a.

Luce, H., Fukao, S., Yamamoto, M., Sidi, C., and Dalaudier, F.: Validation of winds measured by MU radar with GPS radiosondes during the MUTSI campaign, J. Atmos. Ocean. Tech., 18, 817829, 2001 b.

Nash, J., Oakley, T., Vömel, H., and Li Wei: WMO intercomparison of High Quality Radiosonde Systems Yangjiang, China, 12 July3 August 2010, World Meteorological Organisation, Instr. Obs. Methods, p. 107, 2011.

Pavelin, E. and Whiteway, J. A.: Gravity wave interactions around the jet stream, Geophys. Res. Lett., 29, 2024, doi:10.1029/2002GL015783, 2002.

Srinivasa Rao, I., Anandan, V. K., and Reddy, P. N.: Evaluation of DBS wind measurement technique in different beam configurations for a VHF wind profiler, J. Atmos. Ocean. Tech., 25, 23042312, 2008.

Thomas, L., Astin, I., and Worthington, R. M.: A statistical study of underestimates of wind speeds by VHF radar, Ann. Geophys.Italy, 15, 805-812, 1997.

Vaughan, G.: The UK MST radar, Weather, 57, 69-73, 2002.

Weber, B. L. and Wuertz, D. B.: Comparison of rawinsonde and wind profiler radar measurements, J. Atmos. Ocean. Tech., 7, 157-174, 1990.

Waldteufel, P. and Corbin, H.: On the Analysis of Single-Doppler Radar Data, J. Appl. Meteor., 18, 532-542, 1979.

Weber, B. L., Wuertz, D. B., Law, D. C., Frisch, A. S., and Brown, J. M.: Effects of small-scale vertical motion on radar measurements of wind and temperature profiles, J. Atmos. Ocean. Tech., 9, 193-209, 1992.

Worthington, R. M.: Alignment of mountain wave patterns above Wales: a VHF radar study during 1990-1998, J. Geophys. Res., 104, 9199-9212, 1999.

Worthington, R. M., Palmer, R. D., and Fukao, S.: An investigation of tilted aspect-sensitive scatterers in the lower atmosphere using the MU and Aberystwyth VHF radars, Radio Sci., 34, 413-426, 1999a.

Worthington, R. M., Palmer, R. D., and Fukao, S.: Complete maps of the aspect sensitivity of VHF atmospheric radar echoes, Ann. Geophys.-Italy, 17, 1116-1119, 1999b.

Worthington, R. M., Muschinski, A., and Balsley, B. B.: Bias in mean vertical wind measured by VHF radars: significance of radar location relative to mountain waves, J. Atmos. Sci., 58, 707-723, 2001. 